\title{
Características da Atuação do Psicólogo na Proteção Social Especial em Santa Catarina
}

\author{
Fabiani Cabral Lima \\ Universidade Federal de Santa Catarina, SC, Brasil.
}

\author{
Daniela Ribeiro Schneider \\ Universidade Federal de Santa Catarina, SC, Brasil.
}

Resumo: A atuação de psicólogos em um sistema que preconiza a garantia dos direitos sociais da população exige deste profissional a compreensão de fatores políticos, sociais e econômicos que determinam as condições de vida das famílias e indivíduos atendidos no Sistema Único de Assistência Social (SUAS), diretamente relacionadas às situações que produzem as violações de seus direitos. O presente trabalho objetivou caracterizar o trabalho dos psicólogos no Centro de Referência Especializado de Assistência Social (Creas) em Santa Catarina, além de descrever as percepções sobre a atuação do psicólogo nestes dispositivos. Pesquisa exploratória-descritiva, fez uso de métodos mistos. Os dados quantitativos foram coletados a partir da consulta ao CadSUAS. Os dados qualitativos foram obtidos de entrevistas semiestruturadas com 18 profissionais de seis Creas. Foram utilizadas estatísticas descritivas para a análise dos primeiros dados e análise de conteúdo para o trabalho com os segundos. Foram identificados 464 psicólogos cadastrados nos 83 municípios que possuem Creas em Santa Catarina. Quase metade dos profissionais possuem cadastro ativo no Creas e em outros dispositivos da Assistência Social ao mesmo tempo. O vínculo de trabalho mais prevalente entre os psicólogos é o de servidor estatutário, porém $17 \%$ possuem vínculos precarizados. O papel do psicólogo vem se consolidando na direção do atendimento psicossocial, ao migrar de um modelo clínico tradicional, herança do Programa Sentinela, dentro outras raízes, para uma atuação mais integrada na equipe interdisciplinar e ação intersetorial, com foco na atuação social comunitária. Desafios se impõe para a formação e para a luta contra a precarização das condições de trabalho, visando a qualificação dos serviços da Psicologia na proteção social.

Palavras-chave: Sistema Único de Assistência Social, Centro de Referência Especializado de Assistência Social, Papel Profissional, Psicólogo, Sistema de Apoio Psicossocial. 


\title{
The Role of Psychologists in Special Social Protection in the State of Santa Catarina
}

\begin{abstract}
The role of psychologists in a system that advocates the social rights of the population requires these professionals to understand political, social and economic factors that determine the living conditions of families and individuals assisted by the SUAS and are directly related to the situations that produce the violations of these rights. The present study aimed to characterize the work of psychologists in the Creas of Santa Catarina and to describe the perceptions of the role of psychologists in these facilities. Exploratory-descriptive research made use of mixed methods. Quantitative data was retrieved from the CadSUAS, whereas qualitative data came from semi-structured interviews with 18 professionals from six Creas. Descriptive statistics was used for the analysis of the former and content analysis was used to work with the latter. We identified 464 registered psychologists in 83 municipalities that have Creas in Santa Catarina. Almost half of the professionals have active record in Creas and other Social Work bodies at the same time. Most psychologists are employed as statutory servants, but $17 \%$ of them have precarious employment contracts. The role of psychologists is heading toward psychosocial care, i.e., migrating from a traditional clinical model inherited from the Sentinel Program to more integrated activities in multidisciplinary teams and cross-sector actions, with focus on community-based social work. There are challenges related to training these professionals and to fighting precarious working conditions in psychological services of social protection.
\end{abstract}

Keywords: Unique System of Social Assistance, Specialized Reference Center for Social Assistance, Professional Role, Psychologist, Psychosocial Support Systems.

\section{Características de la Actuación del Psicólogo en la Protección Social Especial en Santa Catarina}

Resumen: La actuación de psicólogos en un sistema que preconiza la garantía de los derechos sociales de la población exige de este profesional la comprensión de factores políticos, sociales y económicos que determinan las condiciones de vida de las familias e individuos atendidos en el Sistema Único de Asistencia Social (SUAS), directamente relacionadas con las situaciones que producen las violaciones de sus derechos. El presente trabajo objetivó caracterizar el trabajo de los psicólogos en el Creas en Santa Catarina, además de describir las percepciones sobre la actuación del psicólogo en estos dispositivos. La investigación exploratoria-descriptiva, hizo uso de métodos mixtos. Los datos cuantitativos fueron recolectados a partir de la consulta al CadSUAS. Los datos cualitativos fueron obtenidos de entrevistas semiestructuradas con 18 profesionales de seis Creas. Se utilizaron estadísticas descriptivas para el análisis de los primeros datos y análisis de contenido para el trabajo con los segundos. Se identificaron 464 psicólogos registrados en los 83 municipios que poseen Creas en SC. Casi la mitad de los profesionales poseen registro activo en el Creas y en otros dispositivos de la Asistencia Social al mismo tiempo. El vínculo de trabajo más prevalente entre los psicólogos es el de servidor estatutario, pero el 17\% tiene vínculos precarizados. El papel del psicólogo viene consolidándose hacia la atención psicosocial, al migrar de un modelo clínico tradicional, herencia del Programa Centinela, dentro de otras raíces, para una actuación más integrada en el equipo interdisciplinario y acción intersectorial, con foco en la actuación social comunitaria. Desafíos se impone para la formación y para la lucha contra la precarización de las condiciones de trabajo, visando la calificación de los servicios de la psicología en la protección social.

Palabras clave: Sistema Único de Asistencia Social, Centro de Referencia Especializado de Asistencia Social, Papel Profesional, Psicólogo, Sistemas de Apoyo Psicosocial. 


\section{Introdução}

Um dos principais campos de empregabilidade do profissional psicólogo nos últimos anos tem sido o Sistema Único de Assistência Social (SUAS), implicando inclusive no fenômeno da interiorização da profissão, na medida em que estes profissionais compõe as equipes mínimas de Centro de Referência de Assistência Social (CRAS) e do Centro de Referência Especializado de Assistência Social (Creas) e têm sido contratados em quase todas as cidades brasileiras que vem implantado seus sistemas de proteção social (Macedo \& Dimenstein, 2011). A atuação do psicólogo, enquanto trabalhador da Assistência Social, deve ter como foco, mediado por seu saber e sua técnica, no fortalecimento dos usuários como sujeitos de direitos e na garantia de aplicação das políticas públicas em larga escala (CFP, \& CFESS, 2007).

A trajetória das políticas sociais no Brasil coincide com a história da democratização do país, fomentada pela queda do regime militar. A partir da Constituição da República Federativa do Brasil, de 1988, inicia-se o processo de reconhecimento dos direitos sociais e de reconhecimento da figura do Estado como um dos responsáveis pela garantia desses direitos. Esse processo será materializado, posteriormente, através da implantação de políticas públicas.

É neste contexto que se reconhece a proteção social como direito do cidadão e um dever do Estado, tendo como foco as:

vitimizações, fragilidades, contingências, vulnerabilidades e riscos que o cidadão, a cidadã e suas famílias enfrentam na trajetória de seu ciclo de vida, por decorrência de imposições sociais, econômicas, políticas, culturais e de ofensas à dignidade humana (Brasil, 2013).

Dentre as estratégias de viabilização dessa proteção estão as ações de Assistência Social que se configuram em uma política não contributiva voltada para a universalização de direitos, o enfrentamento da pobreza e para a construção e o provimento de mínimos sociais. Cabe ao SUAS a gestão e a organização da oferta de serviços, programas, projetos e benefícios para aqueles que deles necessitarem. Por meio deste sistema são integradas as ações dos diferentes atores responsáveis pela política de Assistência Social, articulando a oferta pública estatal e não estatal, sob um comando único. A referência para atuação neste sis- tema é o território, levando em consideração as diversidades regionais típicas de um país com abrangência territorial continental, como é o Brasil.

Destaca-se como balizador do trabalho na proteção social a matricialidade sociofamiliar. Seguindo essa diretriz, o trabalho na Assistência Social está centrado na família, desenvolvido por meio de ações de fortalecimento de vínculos e fomento da proteção e socialização do núcleo familiar (Brasil, 2013). A família é considerada, aqui, como núcleo básico para a acolhida, o convívio, a autonomia, a sustentabilidade e o protagonismo social. Seu conceito é ampliado, à medida que envolve os laços afetivos, definindo-se como "núcleo afetivo, vinculada por laços consanguíneos, de aliança ou afinidade, onde os vínculos circunscrevem obrigações recíprocas e mútuas, organizadas em torno de relações de geração e de gênero" (Brasil, 2005). Nesta perspectiva, são negadas ações moralizadoras ou modeladoras dos modos de vida e das crenças dos grupos familiares.

Este trabalho com famílias pode se dar através dos dois níveis de proteção social existentes no SUAS, ou seja, tanto no nível de proteção social básica, quanto no nível de proteção social especial. O que diferencia estes níveis de proteção e, em decorrência disso, a abordagem com as famílias, é o objetivo de cada um.

O primeiro deles tem como objetivo a prevenção de situações de vulnerabilidade e risco social e suas ações se dão por meio do desenvolvimento de potencialidades e aquisições e do fortalecimento de vínculos familiares e comunitários sendo ofertadas por meio do CRAS. Este equipamento é a unidade física onde os serviços, programas e projetos socioassistenciais são ofertados. Tem como finalidade a articulação dos serviços socioassistenciais no seu território de abrangência, e deve estar localizada nas áreas de maiores índices de vulnerabilidade e risco social (Brasil, 2011).

Já o nível de proteção social especial, foco deste artigo, envolve situações nas quais há a violação de direitos. Por isso, tem como objetivo contribuir para a defesa de direitos, o fortalecimento das potencialidades e aquisições, a reconstrução de vínculos familiares e comunitários e a proteção de famílias e indivíduos para o enfrentamento dessas violações. Suas ações se dividem em dois níveis de complexidade, nível de proteção social especial de média complexidade e nível de proteção social especial de alta complexidade.

A proteção social especial de média complexidade tem suas ações executadas na unidade pública que 
pode ter abrangência municipal, estadual ou regional, denominada Creas. O trabalho desenvolvido neste Centro tem como foco a oferta de serviços a indivíduos e famílias que se encontram em situação de risco pessoal ou social por violação de direitos. Já a proteção social especial de alta complexidade tem suas ações voltadas para o atendimento de situações onde os vínculos familiares foram rompidos. Nestes casos, se faz necessário o acolhimento provisório em instituições da Assistência Social a de fim de garantir a proteção integral de famílias elou indivíduos que se encontrem em situação de risco pessoal e social, com vínculos familiares rompidos ou extremamente fragilizados. Destaca-se alguns serviços da proteção social especial, dentre os quais, o Serviço de Proteção e Atendimento Especializado a Famílias e Indivíduos (PAEFI). Este serviço desenvolve ações visando promoção de direitos, preservação e fortalecimento de vínculos e da função de proteção das famílias diante do conjunto de condições que causam fragilidades ou as submetem a situações de risco pessoal e social (Brasil, 2012).

A criação do Creas rompe com a lógica da política de Assistência Social dividida por segmentos sociais (crianças, adolescentes, pessoas com deficiência, idosos) ou tipos de demandas (violência sexual, medidas socioeducativas etc.), ao fazer coexistir serviços antes dispersos na rede socioassistencial e que possuíam pouca ligação entre si, como é o caso do Programa Sentinela, do Serviços de Acompanhamento a Adolescentes em Cumprimento de Medida Socioeducativa, assim como o Serviço de Orientação e Apoio Especializado a Crianças, Adolescentes e Famílias. O objetivo foi o de reunir estas várias ações em um único centro, com a finalidade de ofertar atenção continuada e especializada às famílias e indivíduos com direitos violados (Ribeiro, 2010).

A autora esclarece ainda que o Programa Sentinela (Serviço de Enfrentamento à Violência, Abuso e Exploração Sexual contra Crianças e Adolescentes), implantado em 2001, passou em 2004 a ser um serviço de ação continuada, tendo sido inserido, finalmente, em 2005, como uma das ações do SUAS, a ser incorporado pelos Creas. Sendo assim, como um antigo programa, que possuía estrutura física, material e de recursos humanos, em muitas cidades, o Programa serviu, na verdade, de base para a estruturação de muitos Creas no país (Ribeiro, 2010).

Acomposição das equipes de cada serviço ofertado pela Assistência Social deve obedecer às orientações descritas pela Norma Operacional Básica de Recursos Humanos do SUAS (NOB-RH) (Brasil, 2006), que prevê a presença do psicólogo nas equipes de referências dos CRAS e Creas. Além disso, as diretrizes técnicas de funcionamento de cada serviço são descritas por meio de publicações específicas produzidas pelo Ministério de Desenvolvimento Social (MDS). Os conselhos de classe também atuam como órgãos de regulação da atividade profissional no âmbito da Assistência Social.

Com base na complexidade que envolve o trabalho da proteção social, fica evidente a necessidade de se construir intervenções a partir de uma perspectiva interdisciplinar. Não é possível acreditar que, apenas uma área de conhecimento, seja capaz de dar conta de fenômenos tão complexos e que possuem inúmeros fatores que os determinam. Desta forma, a inclusão dos profissionais da Psicologia nas equipes de referência do SUAS visa contribuir para equacionar as diferentes dimensões intrincadas nos problemas que têm como base a desigualdade social.

Este artigo pretende identificar as características do trabalho dos profissionais da Psicologia nos Creas em Santa Catarina, assim como discutir a percepção sobre o papel desse profissional na consolidação das práticas da proteção social especializada.

\section{O papel da Psicologia no SUAS}

É fundamental que os psicólogos que atuam no SUAS desenvolvam um trabalho crítico de reflexão sobre os fatores que determinam o sofrimento de famílias e indivíduos que necessitam de proteção social. Sofrimento que não deve ser entendido como ontológico, mas que é produzido a partir das relações estabelecidas entre o sujeito e o mundo em que vive, produzindo o que se denomina de sofrimento ético-político (Sawaia, 2009). Esta concepção do sofrimento constitui uma categoria de análise da dialética inclusão/exclusão social. Nela é considerada "a vivência particular das questões sociais dominantes em cada época histórica [...]. Sofrimento que surge da situação de ser tratado como inferior, subalterno, sem valor, apêndice inútil da sociedade" (Sawaia, 2001, p. 56). Nessa direção, a compreensão da vulnerabilidade psicossocial de famílias brasileiras, que acabam por necessitar das políticas públicas de proteção social, deve ser base para o planejamento das ações dos profissionais, evitando a culpabilização dos indivíduos ou da célula familiar, ao fundamentar uma análise mais complexa da situação. 
Consequentemente, a atuação da Psicologia deve superar a tradição subjetivista de visão do mundo e de compreensão do fenômeno psi. Ela parte, assim, do pressuposto de que, apesar de o sofrimento ser vivido pelo indivíduo em sua singularidade, sua gênese é social, o que exige uma clareza na forma de compreender a desigualdade social e a maneira como o psicólogo atua sobre ela (CFP, 2011). Dessa forma, sua atuação no SUAS não deve ter foco no indivíduo, mas nos contextos produtores de vulnerabilidade. Sendo assim, não cabe uma atuação no modelo clínico clássico, mas sim uma ação com foco social comunitário. Estes são caminhos já apontados por alguns estudos, como descreve o estudo de revisão de Motta, Castro e Pizzinato (2015), Ribeiro e Goto (2012) e a dissertação de Ribeiro (2010).

Na análise de sua atuação, contudo, vários estudos verificaram que as ações dos psicólogos ainda não possuem uma base consistente, voltada para as peculiaridades do campo da Assistência Social. Apesar das normativas da Política Nacional de Assistência Social (PNAS), ainda persistem ações de psicólogos no SUAS de caráter exclusivamente clínico tradicional, focadas em práticas psicoterapêuticas (Andrade, \& Romagnoli, 2010; Macêdo, Alberto, Santos, Souza, \& Oliveira, 2015a; Macêdo, Pessoa, \& Alberto, 2015b).

Por outro lado, outros estudos revelaram que as práticas destes profissionais estão sendo desenvolvidas, pouco a pouco, de acordo com as diretrizes de atuação da profissão no contexto da Assistência Social (Reis, \& Cabreira, 2013; Cordeiro, Batista, Carvalho, $\&$ Carmo, 2016). Estes achados indicam que a variação depende dos locais de atuação, da formação que o psicólogo recebeu e do desenvolvimento específico do campo de práticas em cada território.

O desenvolvimento do trabalho social com famílias e indivíduos deve se constituir como norteador do trabalho das equipes do Creas. A concepção de vulnerabilidade e risco social como um evento que emerge em um determinado contexto e que se constitui a partir da ação de inúmeros elementos é essencial para a execução de um trabalho deste nível. A reflexão sobre a complexidade das situações nas quais as famílias e indivíduos usuários deste Centro estão envolvidos permite viabilizar a construção de redes de proteção a medida que se compreende que a atuação isolada, quer seja de um profissional, de um serviço, ou de uma política, não será capaz de dar conta dessa complexidade. Apostar na capacidade das famílias e indivíduos, referenciados no território, é desenvolver um trabalho social de emancipação, auxiliando-os na promoção de sua autonomia com o suporte dos serviços e programas sociais públicos necessários (NECA, 2010).

Os casos acompanhados pelo Creas envolvem violações de direitos e são atravessados por tensões no âmbito individual, familiar e comunitário e podem acarretar na fragilização e até mesmo no rompimento de vínculos (Brasil, 2012). A equipe que não possuir um olhar ampliado sobre estas questões corre o risco de reduzir seu atendimento a uma tecnocracia, a uma burocratização, promovendo, ao invés de garantia, uma nova violação de direitos, uma vez que não viabiliza o acesso a serviços que estimulem a autonomia, àqueles que historicamente estão à margem da proteção social. Este é um desafio para a atuação dos psicólogos, em articulação com as equipes interdisciplinares atuantes no SUAS.

A defesa do compromisso ético e político dos profissionais vinculados à Assistência Social é a diretriz central do SUAS (Brasil, 2006). Compromisso que já está colocado para a Psicologia enquanto ciência e profissão, uma vez que se postula sua ação como forma de atuar frente aos determinantes sociais, econômicas e sociais que produzem sofrimento ético-político (Cordeiro et al., 2016; Macêdo et al., 2015a; Senra, \& Guzzo, 2012).

Ao psicólogo que trabalha com políticas públicas é fundamental a compreensão de que as situações que afetam às famílias e aos indivíduos com os quais ele atende revelam a tonalidade ética da vivência da desigualdade social. E, por isso, seu fazer deve ser posicionado, apontando para a transformação social, para a alteração das condições de vida destas pessoas atendidas (Bock, 1999; Sawaia, 2001). É um compromisso ético do psicólogo neste espaço contribuir para melhorar os fluxos e articulação da rede tendo em vista que o trabalho no Creas é de natureza interdisciplinar, intersetorial e interinstitucional. Dessa forma, "é necessário a 'saída do casulo', do solo das certezas para atuar na multiplicidade do viver cotidiano”, como afirmam Chimainski, Ubessi, Martins e Jardim (2016), atuando junto ao território e sua base comunitária.

Consequentemente, a atuação da Psicologia, no âmbito do SUAS, deve se dar por meio do atendimento psicossocial, segundo relato dos próprios profissionais (Flor, \& Goto, 2015). Isso implica no desafio de se construir respostas diferenciadas que levem em conta as características do território de origem do usuário e que promovam a melhoria das condições 
de vida dos usuários (CFP, 2012). A base desse tipo de intervenção é, então, a contextualização dos processos de vulnerabilidade e violação de direitos, de forma a identificar as determinantes destes processos e auxiliar na mudança destas condições.

Contudo, para que os profissionais do Creas possam realizar seu trabalho de forma ético-política, algumas condições são necessárias, o que implica que "nas políticas sociais é necessário que o profissional psicólogo vá além das normas técnicas da profissão, que ele abdique da posição ingênua e acrítica a respeito dos mecanismos de dominação atual e diagnostique tais aspectos no território de atuação" (Flor, \& Goto, 2015, p. 31). Sendo assim, a proposição de mudanças nos determinantes que produzem desigualdades sociais envolve o questionamento de relações de poder historicamente construídas.

A inserção do psicólogo na política de Assistência Social requer uma investigação ampliada a respeito das condições de trabalho no SUAS. Analisar essas condições significa pautar não só o acesso a direitos para os usuários, mas também a oferta do tipo de contrato de trabalho, de infraestrutura, de salários dignos, de jornada de trabalho condizente com as exigências da categoria, de formação permanente, entre outros aspectos que evitam a precarização do trabalho e garantem condições de qualificação da atuação profissional (CFP, 2012). Impõem-se, portanto, a necessidade de analisar as condições concretas que estão postas para os trabalhadores psicólogos do SUAS, especialmente no que diz respeito aos vínculos de trabalho estabelecidos, posto que estes estão diretamente relacionados com a qualificação dos serviços ofertados para a população.

Sendo assim, o trabalho do psicólogo, que ganha contornos ético-políticos no campo da Assistência Social, necessita de uma análise das condições objetivas que determinam o fazer dos psicólogos que atuam junto a famílias e indivíduos que tiveram seus direitos violados, visando a qualificação de sua atuação. Da mesma forma, necessário se faz discutir os contornos teóricos e técnicos de sua atuação, a fim de avaliar de as ações desenvolvidas estão de acordo com os princípios e exigências da PNAS.

\section{Método}

A pesquisa caracterizou-se como descritiva-exploratória, pois, a partir da descrição das características de determinadas populações ou fenômenos, no caso os psicólogos dos Creas em Santa Catarina (SC), visou proporcionar maior familiaridade com o problema de pesquisa, através da caracterização da atuação desse profissional (Sampieri, Collado, \& Lucio, 1991). Foram utilizados métodos mistos, visando a partir de diferentes formas de aproximação dos dados, triangular sua análise.

Dentro da abordagem quantitativa, foram levantados dados secundários através da consulta a base de dados do Ministério de Desenvolvimento Social e Agrário (MDSA): o CadSUAS, sistema de cadastro com informações de prefeituras, órgãos gestores, fundos e conselhos de Assistência Social, rede socioassistencial e trabalhadores do SUAS em todo território nacional, que foi instituído em 2008, pela Portaria $n^{\circ} 430$. Este sistema é dividido em duas áreas: uma Área Restrita e outra de Consulta Pública. Para a coleta de dados sobre o número de psicólogos vinculados aos Creas e seu perfil institucional, foi realizada a consulta aos dados disponíveis na área de livre acesso deste Sistema. A coleta foi realizada entre os dias 19 e 25 de janeiro de 2017. Foram consultados os dados gerenciais e cadastrais dos 83 municípios que possuem Creas, totalizando 92 equipamentos. Essa diferença entre o número de municípios de equipamentos ocorre porque alguns municípios possuem mais de um Creas.

Já para a abordagem qualitativa coletou-se dados primários, através de entrevistas individuais com 18 profissionais, psicólogos (seis) e não psicólogos (12), vinculados aos Creas de seis municípios do estado de Santa Catarina. Os municípios foram escolhidos com base no índice de desenvolvimento do Creas (IDCREAS) publicado pelo MDSA e que avalia a qualidade destes equipamentos. As entrevistas individuais foram guiadas por um roteiro com nove questões. Aqui neste artigo serão discutidas as respostas para duas perguntas: a) Como você avalia a participação do profissional de Psicologia no processo de implantação do Creas/SC? b) Como você avalia o papel do psicólogo no Creas no contexto atual?

Os dados quantitativos foram inseridos no software Excel, para análise a partir de estatísticas descritivas. Já os dados qualitativos foram trabalhados com análise de conteúdo, segundo o modelo de Ruiz-Olabuénaga (2012).

A análise dos dados foi realizada por grupos, considerando os diferentes tipos de porte dos municípios pesquisados. Para tanto foram considerados os parâmetros de referência para a definição do número de Creas, que descrevem os municípios: de Pequeno 
Porte I (PPI), com população inferior ou igual a 20.000 habitantes; os de Pequeno Porte II (PPII), com população superior a 20.000 e inferior ou igual a 50.000 habitantes; os de Médio Porte, que variam entre 50.001 e 100.000 habitantes; os de Grande Porte, com população superior a 100.000 e inferior ou igual a 900.000 habitantes; e, por fim, as Metrópoles, com população acima de 900.000 pessoas (Brasil, 2010).

Além disso, foram analisados o tipo de vínculo institucional descrito no CadSUAS pelas seguintes categorias: servidor estatutário, empregado público celetista (CLT), servidor temporário, comissionado, outro vínculo não permanente, terceirizado, sem vínculo e trabalhador de empresa/cooperativa/prestadora de serviços. Cabe destacar que estas categorias são definidas pelo CadSUAS. Também foi analisada a quantidade de vínculos que cada profissional possuía, em comparação entre Creas, CRAS e Centro Pop, a fim de verificar se existem trabalhadores cadastrados em mais de um equipamento.

A pesquisa foi respaldada pela Resolução $n^{\circ}$ 466/2012 do Conselho Nacional de Saúde (Brasil, 2012), tendo sido aprovado pelo Comitê de Ética da Universidade Federal de Santa Catarina (UFSC) sob Parecer no 2.229.083.

\section{Resultados e discussão}

\section{Caracterização da inserção dos psicólogos nos Creas de Santa Catarina}

A análise dos dados gerenciais e cadastrais dos 92 Creas de SC revelou a existência de 464 profissionais de Psicologia cadastrados no CadSUAS nestes equipamentos. Este dado revela um aumento do número de psicólogos atuando na proteção social especial em comparação aos dados levantados por pesquisas em anos anteriores. Em 2011, um estudo realizado também a partir dos dados do CadSUAS, identificou a existência de 151 psicólogos atuando em Santa Catarina (Macedo, Sousa, Carvalho, Magalhães, Sousa, \&Dimenstein, 2011). $\mathrm{O}$ atual levantamento de dados revela um aumento de $32,5 \%$ no número de profissionais de Psicologia atuantes dos Creas desse estado, entre os anos de 2011 e 2016, o que é um aumento significativo e indica um campo de atuação em expansão para a categoria.

O aumento do número de psicólogos na proteção social especial pode ser inferido também em âmbito federal. Isso porque, em uma pesquisa realizada em
2009, pelo Centro de Referência Técnica em Psicologia e Políticas Públicas/Conselho Federal de Psicologia (Crepop/CFP), o número de profissionais que responderam atuar no Creas em todo Brasil foi de 522. A atual pesquisa revela que, apenas em SC, este número foi quase alcançado, o que permite inferir o aumento nos demais estados e, consequentemente, o incremento no número de psicólogos atuando nos Creas em todo Brasil.

Com relação a característica dos municípios de atuação destes profissionais, verificou-se que 10,8\% atuam em municípios de PPI, $18,10 \%$ nos de PPII, $13,7 \%$ atuam nos municípios de Médio Porte e 57,3\% estão cadastrados nos de Grande Porte. Em Santa Catarina não existem metrópoles. Estes dados corroboram com os achados de Macedo et al. (2011) que identificaram uma boa expansão dos Creas no território nacional, com destaque para os municípios de maior porte. No entanto, confirma outra faceta interessante no que se relaciona ao papel das políticas públicas na legitimação da profissão, que é a interiorização da atuação da categoria de psicólogos, com quase metade dos profissionais vinculados a municípios de pequeno ou médio porte.

A pesquisa também identificou que a média de profissionais por equipamento aumenta conforme o Porte das cidades. Assim, a média de psicólogos cadastrados em municípios de PPI é de dois por equipamento e de PP II é de 2,7. Já nas cidades de Médio Porte existem 4,2 profissionais por Creas, enquanto nas de Grande Porte existe uma média de 12,6. A NOB-RH define a quantidade de profissionais das equipes de referência conforme o número e o perfil de famílias e indivíduos atendidos, o que justifica a diferença entre as médias encontradas nessa pesquisa, indicando que os municípios, de certa forma, vêm tentando cumprir as exigências legais. Além disso, pode-se atribuir essa distribuição pela maior demanda de indivíduos e famílias em situação de violação de direitos nas cidades maiores, geralmente com índices de violência mais elevados (Macedo et al., 2011).

Destaca-se neste estudo a existência de dois Creas, ambos em municípios de PPI, que não possuem cadastro de psicólogos em seus equipamentos. Em comparação aos dados de 2011, é possível verificar que houve uma diminuição neste tipo de situação, já que haviam sido registrados 157 Creas no Brasil que funcionavam sem a presença destes profissionais naquele momento, sendo que 52 destes encontravam-se na região Sul do 
país (Macedo et al., 2011). A partir dos dados é possível verificar que houve um esforço de normatização da PNAS e da utilização de mecanismos como de repasse de recursos atrelados a um determinado nível de estruturação do SUAS nos municípios, embora ainda existam equipamentos que não possuem equipe de referência completamente estruturada.

Cabe destacar que a presença do psicólogo nas equipes de referência do SUAS foi definida a partir de um amplo debate coletivo baseada nas diretrizes propostas da PNAS e resultou na regulamentação das categorias profissionais que comporiam esse Sistema. A participação dos psicólogos no SUAS, ainda hoje, é vista com desconfiança por aqueles que só conhecem o caráter clínico tradicional da profissão. E isso não se deve à toa. Desde que se configurou como profissão, a Psicologia se colocou, historicamente, atrelada a uma ideologia individualista e neoliberal, servindo, em alguns casos, para corroborar com posições de culpabilização única e exclusiva do sujeito sobre sua condição de vida (Yamamoto, \& Oliveira, 2010). Veremos abaixo que os dados qualitativos corroboram com esta situação. Segundo Botomé (2010), em muitos episódios, ao longo da história da Psicologia no Brasil, os saberes psicológicos foram utilizados a favor da manutenção e incremento do lucro necessário para a manutenção do capital.

Foi investigado também as condições de trabalho no âmbito do SUAS. Para ilustrar essa questão, a pesquisa, relatada neste artigo, investigou o tipo de vínculo institucional que mais prevalece entre os 464 psicólogos que possuem cadastro no CadSUAS no Creas/SC.

Os resultados apontam que, em primeiro lugar, o vínculo mais prevalente de servidor estatutário com $68,10 \%$, em segundo, o de empregado público celetista (CLT) com 12,06\% e, em terceiro lugar, o de servidor temporário com 9,48\% do total de cadastros. Além destes, os cadastros revelaram que $4,74 \%$ dos psicólogos dos Creas possuem vínculo institucional como terceirizados, enquanto $2,58 \%$ são comissionados e 1,72\% possuem outro vínculo não permanente. Já as categorias sem vínculo e trabalhador de empresa /cooperativa/prestadora de serviços representam $0,64 \%$ dos cadastros.

A análise do tipo de vínculo institucional que os 464 psicólogos possuem com os Creas do estado, revelam que ainda que em Santa Catarina a condição de empregabilidade do psicólogo possa ser considerada boa, com mais de $80 \%$ em situação mais estável, ainda assim, existe um percentual significativo de trabalhadores que possuem vínculos precarizados de trabalho. Destaca-se que, do total, $16,95 \%$ estão sujeitos a contratos que não garantem a sua permanência na Assistência Social. A precarização dos vínculos de trabalho e seus prejuízos para o trabalho do psicólogo na Assistência Social são fatores reconhecidos por vários autores (Chimainski et al., 2016; Cordeiro, \& Sato, 2017; Macedo et al., 2011; Oliveira et al., 2014; Senra, \& Guzzo, 2012; Yamamoto, \& Oliveira, 2010), indicando a necessidade de atenção para a qualidade da assistência implementada, uma vez que vínculos de trabalhos precarizados são indicadores de fragilização da atuação profissional.

A precarização dos vínculos de trabalho acarreta em prejuízos no desenvolvimento do trabalho social com famílias e indivíduos no âmbito da Assistência Social, na medida em que o rompimento do vínculo estabelecido com os usuários, em função da rotatividade de profissionais, pode provocar não aderência ao serviço e despotencialização ou interrupções das intervenções psicossociais em andamento (Chimainski et el., 2016; Macedo et al., 2011; Macedo, \& Dimenstein, 2011; Senra, \& Guzzo, 2012).

A atual pesquisa também identificou a existência de profissionais de Psicologia com cadastro ativo no CadSUAS em mais de um equipamento da Assistência Social, o que caracteriza o acúmulo de funções destes profissionais e a não abertura de concursos em muitas prefeituras para novos profissionais, ao reutilizarem seus funcionários para mais de uma função. Conforme os dados encontrados 46,65\% dos psicólogos tem seu cadastro ativo em Creas e CRAS ao mesmo tempo. A maior prevalência desta situação está nos municípios de PPI (24\%) e PPII (19,35\%), porém também ocorre nos municípios de Médio Porte (3\%) e, em menor grau, nos de Grande Porte $(0,3 \%)$. A ocorrência de cadastros realizados simultaneamente em Creas e CentroPop também foi verificada, porém em menor expressividade. Nos municípios de Médio Porte, $1,56 \%$ possuem em suas equipes psicólogos cadastrados nos dois equipamentos, enquanto nas cidades de Grande Porte 0,3\% apresentam esta situação.

$\mathrm{O}$ acúmulo de atribuições dos profissionais de Psicologia que atuam em Creas já foi identificado, anteriormente, pela pesquisa realizada, em 2009, pelo CFP (2011). Dentre os psicólogos entrevistados na época, era recorrente o acúmulo de funções, não apenas com atuações no Creas, mas em toda a Política 
de Assistência Social do Município ou, até mesmo, da política de Saúde e de Educação (Brasil, 2012). O envolvimento de psicólogos que trabalham da Assistência Social em atividades de outras políticas públicas também foi identificado por Macêdo et al. (2015a).

Com base nestes dados, é possível verificar que com os esforços empreendidos desde a criação do SUAS muitas conquistas foram concretizadas, como a implantação de uma política em larga escala neste país com dimensões continentais. $\mathrm{O}$ aumento do número de contratações de psicólogos nos Creas, como vimos acima, indica a força da expansão dessa política, que vinha ocorrendo até 2016, momento da coleta dos dados. Porém, ainda existem muitas dificuldades a serem superadas a fim de se consolidar as diretrizes da PNAS. Dificuldades como a tendência de precarização dos vínculos, a alta rotatividade, a falta de preparo para o desempenho de funções na esfera municipal e as condições de trabalho precárias (Andrade, \& Romagnoli, 2010; Cordeiro, \& Sato, 2017; Senra, \& Guzzo, 2012; Silveira, 2011). A porta de entrada para as ações de precarização do trabalho é, justamente, a flexibilização dos vínculos de trabalho (Raichelis, 2011) identificada pelos dados desta pesquisa como presente, ainda que não de forma tão intensa, nos equipamentos de média complexidade do SUAS e que certamente ocorre nos demais níveis e equipamentos deste Sistema.

Passaremos agora a discutir aspectos relacionados aos sentidos da atuação do psicólogo na Assistência Social, de como ela é percebida pelos próprios psicólogos e por colegas do Creas, da gestão e dos conselhos tutelares.

\section{Percepções sobre o papel dos psicólogos na implantação e consolidação do Creas}

O entendimento dado ao termo "percepção" diz respeito à maneira como os profissionais participantes da pesquisa analisaram, avaliaram e qualificaram a atuação do psicólogo no Creas/SC (Faraj, Siqueira, \& Arpini, 2016).

Em termos da história da implantação do Creas em Santa Catarina, a experiência dos psicólogos em outros serviços da Assistência Social foi considerada como uma contribuição importante para a implantação do Creas. Isso porque, para estes profissionais, o conhecimento da rede de garantia de direitos e do trabalho em equipe por psicólogos deu base para o desenvolvimento do trabalho na perspectiva psicossocial nos novos dispositivos.
Foi assinalado a importância do Programa Sentinela, como política anterior na Assistência Social, voltada para o atendimento às Crianças e Adolescentes vítimas de violência, para a consolidação do Creas, por ser um campo de práticas já consolidado e ter profissionais com experiências efetiva na atenção a estes fenômenos, entre os quais, muitos psicólogos. O trabalho desenvolvido nos programas de combate e enfrentamento a violência, pelos estes profissionais, proporcionou uma bagagem de conhecimento a respeito do trabalho desenvolvido com a rede de garantia de direitos que foi um dos pilares para a construção do Creas.

Muito importante a presença da psicóloga, naquela época. Na verdade, era nosso ponto de referência. Ela (a psicóloga do Sentinela) tinha mais conhecimento, já trabalhava com a questão da violência há muito tempo, e era a pessoa que nos orientava, que nos dava suporte ( $\mathrm{P} 07$, pedagogo).

Na avaliação dos próprios psicólogos que passaram por esta transição na política, a bagagem trazida não só auxiliou no desenvolvimento do trabalho do Creas, como também proporcionou segurança diante das mudanças paradigmáticas propostas durante a transição do programa Sentinela para o Creas:

Dos profissionais novos, eu já escutei muitas vezes a história de "cair de paraquedas". Eu, que vinha da experiência do Sentinela, me sentia mais fundamentada, não sei se é bem essa palavra, mas acho que sim. Mesmo tendo que me adaptar, passar do modelo da psicoterapia para o atendimento psicossocial, eu me sentia mais fundamentada do que quem chegava cru dos concursos havidos de 2010 em diante (P17, psicólogo).

Com a determinação da criação dos Creas nos municípios que ofertavam o Programa Sentinela, estes precisaram se adequar aos critérios da nova política, para que houvesse o reconhecimento da implantação dos equipamentos previstos e o consequente recebimento dos recursos financeiros do Governo Federal (Ribeiro, 2010). Sendo assim, a metodologia de trabalho dos psicólogos no Sentinela, que ocorria, na maioria das vezes, com sustentação no enfoque clínico tradicional, voltado para o acolhimento dos sujeitos singulares, justaposto ao trabalho do assistente social, com enfoque mais na atenção às famílias, represen- 
tou um desafio a ser desconstruído, como vemos no depoimento abaixo:

Porque o viés nosso ainda era aquele viés do Sentinela. Sendo assim, a psicóloga trabalhava com a vítima, no caso, e eu, assistente social, trabalhava a família. Na época as nossas atuações se davam em separado, a psicóloga ficava lá, trabalhava com aqueles bonequinhos e eu ficava com a família no atendimento. Hoje é completamente diferente, é outra lógica (P04, coordenador de Creas).

Desta forma, é fundamental compreender a transição paradigmática que a implementação do SUAS trouxe para o campo da proteção social, desafiando profissionais a quebrar modelos teórico e metodológicos antes consolidados e a construir um olhar da integralidade sobre a questão dos direitos humanos e vulnerabilidades sociais, instigando o campo da formação profissional a renovar-se. Este histórico ajuda na compreensão do campo de tensões existente no que se refere à racionalidade técnica da atuação no SUAS, que oscila entre as forças conservadoras, que trazem o modelo clínico tradicional, como enfoque no indivíduo, numa visão liberal e ahistórica dos fenômenos e o modelo psicossocial, com a visão da complexidade e integralidade do sujeito e de seu contexto, implicando na exigência de uma atuação interdisciplinar, com foco no fortalecimento dos vínculos familiares e no contexto comunitário.

A Psicologia que se tinha no Sentinela era uma coisa um pouco diferente do que temos hoje. Então, essa transição, para essa outra forma de atender, do psicossocial, foi se dando de forma lenta. Até porque tu estás há anos trabalhando de um jeito e os profissionais são os mesmos, então é meio complicado. A partir de que foi sendo exigido a mudança, e que foi entrando mais gente da área da Psicologia no Creas aí que é que foi transformando, procurando novas orientações, é que o pessoal foi mudando (P10, educador social).

Os profissionais de Psicologia que não possuíam experiência anterior na Assistência Social, muitos vindo de atuações anteriores no contexto da saúde, tinham maior tendência de reproduzir o modelo clínico tradicional: "Ah, eu no início aqui fazia clínica! Eu não sabia! Eu atendia todo mundo individual"
(P01, psicólogo). Nestes casos, em que os psicólogos entraram sem experiência anterior na área, foi necessário um processo construção de uma nova forma de atuação, mediada pelos colegas de equipe, e pelas orientações tanto da política, quanto das orientações técnicas fornecidas pelos Conselhos de Psicologia, considerado por muitos como um importante subsídio para a consolidação de uma atuação qualificada dos psicólogos na nova política. Estudo específico sobre a atuação de psicólogos nos Creas de cidades de pequeno porte revela achados na mesma direção, ao demostrar que muitos psicólogos entram no serviço sem clareza das ações que são esperadas de sua profissão e buscam no diálogo com a equipe e na leitura das diretrizes da política e da profissão, construir a sua trajetória de inserção (Silva, \& Cezar, 2013).

Eu não sei explicar muito isso, porque nós também nos perdemos, nós sabíamos fazer psicoterapia e não podíamos mais fazer, e quem chegou novo não sabia o que fazer na assistência. Como vivenciamos a construção da nova política com a equipe, nós pensamos que não podíamos mais fazer psicoterapia, mas alguma coisa nós tínhamos que fazer. $\mathrm{E}$ fomos pouco a pouco... O meu olhar de psicóloga está acima de tudo, desde a visita domiciliar que eu faço até outras ações (P17, psicólogo).

É interessante notar que outros estudos também descrevem esta apropriação dos psicólogos do SUAS da exigência de superação do modelo clínico tradicional, como sendo um imperativo para a atuação no campo, ainda que se questionem ou não tenham certeza do que colocar no seu lugar (Flor, \& Goto, 2015).

Após a publicação das orientações da própria política e do Crepop (CFP, 2011), foi sendo gerado um processo de debates a respeito do trabalho do psicólogo no Creas e a proposta de atendimento psicossocial foi se consolidando como orientação técnica para o campo de práticas. As equipes passaram a rever seus processos de trabalho e a realizar alterações necessárias para que esse atendimento fosse se realizando em uma perspectiva interdisciplinar, como pode ser observado no relato abaixo:

Hoje a gente tá com um trabalho mais redondo, porque eu e a assistente social estamos trabalhando melhor juntas. Então, teve uma adaptação: quando a gente entrou, as mesas não 
ficavam na mesma sala, não tinha uma sala de técnicos, eu tinha uma sala e ela tinha a sala dela. Isso prejudicava muito, porque aí a nossa comunicação era prejudicada, era muito setorizado, Psicologia, Assistência Social, não tinha o psicossocial. Então, hoje já tem muito mais integração (P08, psicólogo).

Outras pesquisas vêm mostrando o ganho que representa na qualificação da atuação dos psicólogos no SUAS a sua inserção nos trabalhos em equipe interdisciplinar, ao propiciar uma percepção mais abrangente e integrada das ações desenvolvidas pela rede de Assistência Social nas comunidades, construindo espaços de reflexão entre profissionais de diferentes áreas que subsidiem a construção de propostas de trabalhos voltadas para a realidade concreta de seus usuários (Chimainski et al., 2016; Macedo, \& Dimenstein, 2011).

A proposta de atendimento psicossocial passou a exigir uma mudança de foco dos profissionais da Psicologia, mais voltado para a violação de direitos das famílias e indivíduos atendidos. Essa mudança representa muito mais do que uma questão metodológica, de atendimento em dupla por parte dos assistentes sociais e psicólogos. Ela exige a leitura da complexa realidade envolvida, com base nos determinantes sociais destas situações de violação de direitos e, sobretudo, no sofrimento ético-político produzido por estes determinantes, que incidem sobre a produção da subjetividade da população (Sawaia, 2001).

Esta mudança de olhar proposta como metodologia de trabalho no Creas é um dos maiores desafios enfrentados pelos profissionais da Psicologia:

Foram anos de aprendizado, não foi uma coisa do dia para a noite, e até o nosso manejo com os usuários mudou, foi um período de transição difícil. Foi um processo com base de muita leitura, de muito estudo, de vontade própria, de nós termos esse entendimento de que precisávamos se readaptar e entender melhor o contexto de trabalho. Não que a gente tenha tido capacitação específica quanto a isso; nós tivemos capacitações falando sobre o SUAS, como que funcionava, sobre o serviço, o que se fazia, qual o público, qual o objetivo, mas para nós, psicólogos, entender e ter um passo a passo de como atuar, do que se fazer e o que não fazer, isso nós tivemos que fazer por conta própria e aí foi um processo de transição longo. Eu lembro muito que nós tivemos que perder esse olhar da psicoterapia, abrir mão dele. E aí temos essa dificuldade com a política de saúde pública até hoje (P17, psicólogo).

$\mathrm{O}$ atendimento psicossocial implica, para além da atuação interdisciplinar, o enfoque intersetorial, no qual os campos de atuação são bem delimitados e complementares. Essa condição de atuar em rede, com referenciação entre diferentes setores, como a saúde, a educação, a justiça, entre outras, depende, para sua efetivação, da compreensão do que é o modo psicossocial no SUAS.

O psicossocial é bem diferente do atendimento clínico. Tu podes até focar algumas vezes em diagnosticar um transtorno. Mas não é aquilo que tu vais tratar. E isso a gente costuma sempre deixar bem claro para o usuário, principalmente quando ele vem, assim, de uma relação de abuso sexual, que geralmente deixa algum trauma, deixa algumas cicatrizes, então é esclarecido, a gente vai trabalhar o apoio, as orientações, $\mathrm{o}$ acesso aos direitos, mas dependendo do nosso andamento aqui, a gente encaminha para a rede para fazer 0 acompanhamento clínico (P11, psicólogo).

As práticas interdisciplinares e as ações intersetoriais, conforme verificado em outros estudos, têm sido consideradas importantes nessa mudança paradigmática, pois a articulação em rede potencializa a ação integral junto às famílias, ao visar a autonomia dos sujeitos, o fortalecimento dos vínculos, a promoção da saúde e a prevenção de vulnerabilidades (Chimainski et al., 2016; Motta, \& Scarparo, 2013).

No entanto, conforme a condição de apropriação do que é atuar em termos psicossociais, da formação recebida para atuar na área, podem ocorrer mal-entendidos e distorções sobre o papel do psicólogo, com a manutenção do olhar tradicional.

O papel do psicólogo, eu vejo assim ó, aqui o meu serviço não é de psicólogo, entende? Esse trabalho que a gente faz é psicossocial, de orientação. A pessoa pode chegar aqui surtando, eu vou encaminhar ela pro CAPS. Então o que eu faço, o meu objeto de estudo no Creas é a violação de direito, é o abuso sexual, é a violência contra a mulher, é violência contra o idoso, não é depressão, não é 
estresse, não é pânico. Quando tem esses sintomas, a gente tem que encaminhar para o outro equipamento. Então isso não é trabalho do psicólogo, isto é, o nosso trabalho é um trabalho psicossocial (P05, psicólogo).

Este relato indica que a consolidação do atendimento psicossocial ainda está fragilizada e representa uma questão central para a construção da identidade profissional do psicólogo que atua no Creas. Identidade que é vital para o desenvolvimento de um trabalho pautado no compromisso ético-político da profissão e que está diretamente relacionada a outras questões levantadas neste estudo, como o conhecimento a respeito da política pública de Assistência Social e a experiência na área, como constatado, também, constatado por outros estudos (Silva, \& Cezar, 2013).

Os usuários, assim como outros profissionais e outros dispositivos da rede de atenção muitas vezes, também não têm clareza desse modo de atendimento, exigindo do psicólogo a atuação clínica tradicional. Segundo o relato, esse desconhecimento foi mais forte no início da implantação do Creas, pois ainda não se tinham clareza da delimitação desse novo olhar e de forma de atuação. Porém, em muitas situações, é pontuada que essa ambiguidade ainda persiste.

Houve uma discussão muito grande, porque daí o psicólogo deixou de fazer psicoterapia e entrou para a assistência para fazer Psicologia Social, e aí, também, houve a resistência do gestor, a resistência de colegas da saúde, que entendiam que o psicólogo tinha que continuar fazendo psicoterapia. Então, até hoje as pessoas não entendem, até hoje cobram do psicólogo que faça psicoterapia na assistência, e não é aqui o local para isso. Psicólogo para fazer psicoterapia tem que tá lá na saúde, tem que tá em centros que a gente possa encaminhar. Não pode ser aqui na assistência (P16, coordenador de Creas).

Um estudo sobre o olhar de operadores de direito e conselheiros tutelares sobre a atuação do psicólogo no Creas indica ainda uma expectativa de atuação mais tradicional, na medida em que compreendem que embora nem todas as vítimas de violência apresentem problemas emocionais, em todas as situações é imprescindível avaliar e realizar o encaminhamento para o acompanhamento (Faraj et al., 2016). Na presente pesquisa, os psicólogos queixaram-se de que os operadores da justiça solicitam atividades para além de suas competências dentro do Creas, como peritagem, avaliação psicológica, estudo social, que fogem de suas atribuições.

Apesar destas ambiguidades, vem consolidando-se, pouco a pouco, a concepção sobre as especificidades da contribuição do saber psicológico no campo da Assistência Social, trazendo esta complementaridade de olhares com os assistentes sociais, pedagogos, operadores de direitos, conselheiros e outros profissionais envolvidos no Creas.

O psicólogo é aquele que vem trazer o seu olhar da questão mesmo, da reestrutura familiar, do fortalecimento dos vínculos, do trabalho com a autoestima da pessoa vítima de violência. Então, cada um com o seu olhar, dentro da sua ótica, mas trabalhando alinhado. A possibilidade de êxito com a família passa a ser bem maior (P16, coordenador do Creas).

Eu acho que a Psicologia quebra muito esse preconceito, esse achismo popular, por exemplo: que a mulher apanha porque gosta, que não entende que existe todo uma pressão, a violência psicológica, que não conseguia entender, era muito difícil entenderem o que é sofrer e o que é realizar um ato violento. Então a Psicologia, porque eu vou num limite, a Psicologia me completa nessa parte, completa o meu trabalho, porque ela vai esclarecer esses pontos (P13, técnico de gestão).

Outros estudos também discutem as contribuições específicas do psicólogo para o SUAS, como, por exemplo, os aportes para o desenvolvimento da própria equipe do serviço, a compreensão integral, incluindo a dimensão subjetiva, dos fenômenos psicossociais implicados na promoção da proteção social, que auxilia na garantia dos direitos humanos. (Motta, \& Scarparo, 2013; Silva, \& Cezar, 2013). Nessa direção, discute-se que a especificidade "do olhar do psicólogo sobre o sujeito, fortalece o momento da acolhida, podendo determinar a permanência ou não dos sujeitos e suas famílias na adesão do atendimento (Silva, \& Cezar, 2013, p. 92). 
De qualquer modo, a inserção do psicólogo do Creas exige um foco para a atuação em espaços coletivos e comunitários, colocando-se como desafio a superação da formação profissional muito centrada em saberes sobre subjetividades e das expectativas geradas sobre uma atuação clínica individual. Como chamam atenção Chimainski et al. (2016), a atuação no SUAS exige deslocamentos dos saberes e práticas acomodados na tradição, instigando a "saída do casulo", para adentrar em novas práticas de fato integrativas, interdisciplinares e intersetoriais.

\section{Considerações finais}

Os objetivos propostos de caracterizar o trabalho dos profissionais da Psicologia nos Creas em Santa Catarina, assim como discutir a percepção sobre o papel desse profissional na consolidação das práticas da proteção social especializada, foram alcançados a partir de métodos mistos de pesquisa.

A participação dos psicólogos no SUAS tem sido considerada como fundamental, ao trazer suas contribuições específicas, como o aprofundamento da dimensão psicossocial relacionada às vivências das famílias e os indivíduos envolvidos em violação de direitos. Esta participação deve ser contextualizada a partir dos referenciais normativos da PNAS, mas, principalmente, deve estar balizada nos princípios éticos e no compromisso político da profissão.

O trabalho dos psicólogos no SUAS está passando por um processo de transição, que envolve a superação de práticas de caráter clínico tradicional, com sustentação teórico metodológica com foco no indivíduo, em um olhar patologizante, e um enquadre descontextualizado, para a assimilação de novos saberes e fazeres psi, atentos às demandas sociais, ao olhar da complexidade dos fenômenos e à exigência de uma atuação interdisciplinar e intersetorial. Cabe não só aos profissionais atuantes na área, como também às entidades responsáveis pela formação, pela regulamentação e pela pesquisa em Psicologia a construção desses novos saberes e fazeres.

O estudo revelou que o Creas, apesar de ser um campo de trabalho em expansão para a categoria, auxiliou na interiorização de psicólogos no estado de Santa Catarina, constituindo-se em um mercado de trabalho atrativo para a categoria. A atuação dos psicólogos nos Creas em Santa Catarina teve bons critérios de contratação através de concursos públicos e vínculos mais estáveis de trabalho. Por outro lado, ainda ocorre em muitos locais vínculos de trabalho precarizados e ações fragmentadas. Os prejuízos que estas condições acarretam para os profissionais, em um nível pessoal, assim como para a qualidade do trabalho psicossocial desenvolvido são inúmeros. E, apesar dos esforços dos legisladores e defensores da Política de Assistência Social, ainda há muito que se avançar.

A consolidação da Proteção Social Especial no estado de Santa Catarina deu-se, entre outras vias, pela transformação de dispositivos anteriores da política de Assistência Social, como por exemplo, o Programa Sentinela. Este, por ser um campo de práticas já consolidado e ter equipes de referência com experiências efetivas na atenção ao fenômeno da violência, auxiliou na construção do Creas neste estado, inclusive com importante atuação dos psicólogos. No entanto, esta situação trouxe impasses paradigmáticos, pois impôs o desafio da desconstrução da racionalidade anterior sobre o campo, visando a adoção das novas exigências de princípios e fundamentos técnicos para o SUAS. Nesse sentido, esta origem histórica é um dos aspectos que pode estar relacionado à permanência de forças conservadoras na atuação dos psicólogos dentro de dispositivos da Assistência Social, ainda muito marcada pela lógica da clínica tradicional. Outros aspectos, como a necessidade de atualização das formações universitárias, também podem estar na origem dessa questão, exigindo uma revisão dos currículos dos cursos de Psicologia, que deveriam focar-se mais na atualização das políticas sociais e nos fundamentos para a atuação dos psicólogos em no âmbito do SUAS.

Coloca-se, desta forma, como um desafio, a consolidação da fundamentação consistente do atendimento psicossocial no Creas, ligado à Psicologia social comunitária, que, pouco a pouco, vem esclarecendo seus caminhos teóricos, procedimentos técnicos e ações integrais, com foco na atuação interdisciplinar e em ações intersetoriais com outras políticas públicas, visando a proteção integral às famílias e indivíduos em situação de vulnerabilidade.

É imprescindível que os profissionais da Psicologia que trabalham no SUAS assumam o compromisso social proposto e atuem de forma posicionada, criticamente, na direção da mudança das determinantes da desigualdade social, para que assim, atue verdadeiramente como um agente garantidor de direitos 
É importante ressaltar que o país passa, nos últimos dois anos, por ações de desmonte das políticas públicas e da garantia de direitos sociais da população, sendo que o SUAS é uma das políticas mais visadas em seu desmantelamento. Sendo assim, a qualificação do fazer profissional dentro de seus dispositivos, como uma forma de qualificar o cuidado e a proteção social, é uma forma de fazer com que a população tenha experiências concretas de proteção e inclusão social, o que pode torna-se uma importante estratégia de luta pela permanência da política.

Esta pesquisa teve algumas limitações, entre elas a consulta ao CadSUAS, que permitiu descrições mais gerais da inserção dos psicólogos nos Creas/SC, mas sem obter dados mais detalhados que caracterizariam os vínculos profissionais, pois não se obteve registros sobre remuneração, tempo de inserção, experiências anteriores etc., que poderiam aprofundar a análise das condições de trabalho. Da mesma forma, a pesquisa qualitativa envolveu a participação de profissionais de somente seis municípios, o que pode não caracterizar a realidade de todo o estado de Santa Catarina e impor limites para a generalização de seus achados. Ainda assim, a pesquisa apontou alguns dados muito interessantes para pensar o campo da Assistência Social Especial e o papel do psicólogo no desenvolvimento e na consolidação dessa política.

\section{Referências}

Andrade, L. F., \& Romagnoli, R. C. (2010). O psicólogo no CRAS: Uma cartografia dos territórios subjetivos. Psicologia: Ciência e Profissão, 30(3), 604-619.

Bock, A. M. B. (1999). A Psicologia a caminho do novo século: Identidade profissional e compromisso social. Estudos de Psicologia, 4(2), 315-329. https://doi.org/10.1590/S1413-294X1999000200008

Botomé, S. P. (2010). A quem nós, psicólogos, servimos de fato? In O. Yamamoto, A. L. F. Costa (Org.), Escritos sobre a profissão de psicólogo no Brasil (pp. 171-203). Natal, RN: EDUFRN.

Brasil. (2012). Orientações técnicas: Centro de Referência Especializado de Assistência Social - CREAS. Brasília, DF: Ministério do Desenvolvimento Social e Combate à Fome.

Brasil. (2013). Secretaria Nacional de Assistência Social. Caderno de estudos do curso de indicadores para diagnóstico do SUAS e do Plano Brasil sem Miséria. Brasília, DF: Secretaria de Avaliação e Gestão da Informação.

Brasil. (2006). Secretaria Nacional de Assistência Social. Norma operacional básica de recursos humanos do SUAS. Brasília, DF: Ministério do Desenvolvimento Social e Combate à Fome.

Brasil. (2005). Secretaria Nacional de Assistência Social. Política nacional de Assistência Social, PNAS/2004. Brasília, DF: Ministério do Desenvolvimento Social e Combate à Fome.

Chimainski, C., Ubessi, L. D., Martins, S. S., \&Jardim, V. M. R. (2016). Atuação do(a) profissional de psicologia em sistemas de proteção social brasileiros. Mudanças - Psicologia da Saúde, 24(1), 55-63. https://doi.org/10.15603/21761019/mud.v24n1p55-63

Conselho Federal de Psicologia - CFP. (2011). Como os psicólogos e as psicólogas podem contribuir para avançar o Sistema Único de Assistência Social (SUAS): Informações para gestores e gestoras. Brasília, DF: CFP. Recuperado de http://site.cfp.org.br/wp-content/uploads/2011/12/GestoresSuasfinal.pdf

Conselho Federal de Psicologia - CFP. (2012). Referências técnicas para prática de Psicólogas (os) nos Centros de Referência Especializado de Assistência Social - CREAS. Brasília, DF: CFP

Conselho Federal de Psicologia - CFP, \& Conselho Federal de Serviço Social - CFESS. (2007). Parâmetro para atuação de assistentes sociais e psicólogos(as) na Política de Assistência Social. Brasília, DF: CFP/CEFESS.

Cordeiro, M. P.; Batista, J. T.; Carvalho, S.; \& Carmo, L. (2016). Psicología en la Asistencia Social: La construcción de una práctica comprometida. Quadernos de Psicología, 18(1), 21-33. https://doi.org/10.5565/rev/qpsicologia.1304.

Cordeiro, M. P., \& Sato, L. (2017). Psicologia na política de Assistência Social: Trabalho em um "setor terceirizado". Estudos de Psicologia(Campinas), 34(1), 41-52. httpS://doi.org/10.1590/1982-02752017000100005.

Faraj, S. P., Siqueira, A. C., \& Arpini, D. M. (2016). O atendimento psicológico no Centro de Referência Especializado da Assistência Social e a visão de operadores do direito e conselheiros tutelares. Estudos de Psicologia (Campinas), 33(4), 757-766. https://doi.org/10.1590/1982-02752016000400018 
Flor, T. C., \& Goto, T. A. (2015). Atuação do psicólogo no CRAS: Uma análise fenomenológico-empírica. Revista da Abordagem Gestáltica, 21(1), 22-34.

Macedo, J. P., \& Dimenstein, M. (2011). Expansão e interiorização da Psicologia: Reorganização dos saberes e poderes na atualidade. Psicologia: Ciência e Profissão, 31(2), 296-313. https://doi.org/10.1590/S1414-98932011000200008

Macedo, J. P., Sousa, A. P. S., Carvalho, D. M., Magalhães, M. A., Sousa, F. M. S., \& Dimenstein, M. (2011). O psicólogo brasileiro no SUAS: Quantos somos e onde estamos? Psicologia em Estudo, 16(3), 479-489. https://doi. org/10.1590/S1413-73722011000300015

Macêdo, O. J. V., Alberto, M. F. P., Santos, D. P., Souza, G. P., Oliveira, V. S. (2015a). Ações do profissional de Psicologia no Centro de Referência de Assistência Social. Psicologia: Ciência e Profissão, 35(3), 809-823. https://doi. org/10.1590/1982-3703001632013.

Macêdo, O. J. V., Pessoa, C. B. P., Alberto, M. F. P. (2015b). Atuação dos profissionais de Psicologia junto à infância e à adolescência nas políticas públicas de Assistência Social. Psicologia: Ciência e Profissão, 35(3), 916-931. https:// doi.org/10.1590/1982-3703000922014

Motta, R., Castro, T. G., \& Pizzinato, A. (2015). A psicologia nos Centros de Referência de Assistência Social (CRAS): Um panorama das publicações científicas brasileiras de 2004 a 2014. Liberabit, 21(2), 341-348.

Motta, R. F., \& Scarparo, H. B. K. (2013). A psicologia na Assistência Social: transitar, travessia. Psicologia \& Sociedade, 25(1), 230-239. https:// doi.org/10.1590/S0102-71822013000100025

NECA - Associação dos Pesquisadores de Núcleos de Estudos e Pesquisas sobre a Criança e o Adolescente. (2010). Redes de proteção social (Coleção Abrigos em Movimento). São Paulo: Associação Fazendo História.

Oliveira, I. F., Oliveira, N. L. A., Nascimento, M. N. C., Araújo, R. L., Coelho -Lima, F., \& Amorim, K. M. O. (2014). A atuação dos psicólogos no CRAS do interior do RN. Psicologia \& Sociedade, 26(n esp 2), 103-112. https://doi. org/10.1590/S0102-71822014000600011

Portaria no 842, de 28 de dezembro de 2010. (2010, 29 de dezembro). Dispõe sobre o cofinanciamento federal, por meio do Piso Fixo de Média Complexidade - PFMC, dos serviços socioassistenciais ofertados pelos Centros de Referência Especializados de Assistência Social - CREAS e pelos Centros de Referência Especializados para População em Situação de Rua, e dá outras providências. Diário Oficial da União.

Raichelis, R. (2011). O trabalho e os trabalhadores do SUAS: o enfrentamento necessário na Assistência Social. In: J. Crus (Org.), Gestão do trabalho no âmbito do SUAS: Uma contribuição necessária para ressignificar as ofertas e consolidar o direito socioassistencial (pp. 41-66). Brasília, DF: MDS.

Reis. R. G., Cabreira, L. (2013). As políticas públicas e o campo: E o psicólogo com isso? Psicologia: Ciência e Profissão, 33(n esp), 54-65.

Ribeiro, A. B. (2010). O psicólogo na proteção social especial: Atuação junto às vítimas de violação de direitos no CREAS (Dissertação de Mestrado). Universidade Federal do Rio Grande do Norte, Natal, RN, Brasil.

Ribeiro, M. E., \& Goto, T. A. (2012). Psicologia no sistema único de Assistência Social: Uma experiência de clínica ampliada e intervenção em crise. Gerais: Revista Interinstitucional de Psicologia, 5(1), 184-194.

Ruiz- Olabuénaga, J. (2012). Metodologia de la investigación cualitativa. Bilbao: Ed. Univ. de Deusto.

Sampieri, R. H., Collado, C. F., \& Lucio, P. B. (1991). Metodología de la investigación. México, DF: McGraw- Hill Interamericana de México.

Sawaia, B. B. (2001). O sofrimento ético-político como categoria de análise da dialética exclusão/inclusão. In: B. B. Sawaia (Org.), As artimanhas exclusão: Análise psicossocial e ética da desigualdade social (2a ed., pp 97-118). Petrópolis, RJ: Vozes.

Sawaia, B. B. (2009). Psicologia e desigualdade social: Uma reflexão sobre liberdade e transformação social. Psicologia \& Sociedade, 21(3), 364-372. https://doi.org/10.1590/S0102-71822009000300010

Senra, C. M. G., \& Guzzo, R. S. L. (2012). Assistência social e psicologia: Sobre as tensões e conflitos do psicólogo no cotidiano do serviço público. Psicologia \& Sociedade, 24(2), 293-299. https://doi.org/10.1590/S010271822012000200006

Silva, R. B., \& Cezar, P. C. N. (2013). Atuação do psicólogo no CREAS em municípios de pequeno porte. Estudos Interdisciplinares em Psicologia, 4(1), 80-98. https:// doi.org/10.5433/2236-6407.2013v4n1p80 
Silveira, J. I. (2011). Gestão do trabalho: Concepção e significado para o SUAS. In J. Crus (Org.), Gestão do trabalho no âmbito do SUAS: Uma contribuição necessária para ressignificar as ofertas e consolidar o direito socioassistencial (pp. 11-40). Brasília, DF: Secretaria Nacional de Assistência Social.

Yamamoto, H. O., \& Oliveira, I.F. (2010). Política social e Psicologia: Uma trajetória de 25 anos. Psicologia: Teoria e Pesquisa, 26(n esp.), 9-24. https://doi.org/10.1590/S0102-37722010000500002

\section{Fabiani Cabral Lima}

Psicóloga. Doutoranda do Programa de Pós-graduação da Universidade Federal de Santa Catarina, Florianópolis SC. Brasil.

E-mail: fabiani.lima@hotmail.com

Daniela Ribeiro Schneider

Psicóloga. Docente do Programa de Pós-graduação em Psicologia da Universidade Federal de Santa Catarina, Florianópolis - SC. Brasil.

E-mail: danischneiderpsi@gmail.com

Endereço para envio de correspondência:

Núcleo de Pesquisas em Clínica da Atenção Psicossocial - PSICLIN. Departamento de Psicologia. Universidade Federal de Santa Catarina. Campus Universitário. Caixa Postal: 476. Bairro Trindade. CEP: 88040-900.

Florianópolis - SC - Brasil.

Recebido 26/04/2017

Reformulado 26/10/2017

Aprovado 21/02/2018

Received 04/26/2017

Reformulated 10/26/2017

Approved 02/21/2018

Recibido 26/04/2017

Reformulado $26 / 10 / 2017$

Aceptado 21/02/2018

Como citar: Lima, F. C., \& Schneider, D. R. (2018). Características da atuação do Psicólogo na proteção social especial em Santa Catarina. Psicologia: Ciência e Profissão, 38(2), 347-362. https://doi.org/10.1590/1982-3703001402017

How to cite: Lima, F. C., \& Schneider, D. R. (2018). The role of Psychologists in special social protection in the State of Santa Catarina. Psicologia: Ciência e Profissão, 38(2), 347-362. https://doi.org/10.1590/1982-3703001402017

Cómo citar: Lima, F. C., \& Schneider, D. R. (2018). Características de la actuación del Psicólogo en la protección social especial en Santa Catarina. Psicologia: Ciência e Profissão, 38(2), 347-362. https://doi.org/10.1590/1982-3703001402017 